\title{
Mentorship of expatriates in transnational companies
}

\author{
Herbert-Hansen, Zaza Nadja Lee; Rasmussen, Lauge Baungaard
}

Published in:

Journal of Global Mobility

Link to article, DOI:

10.1108/JGM-05-2015-0018

Publication date:

2016

Document Version

Peer reviewed version

Link back to DTU Orbit

Citation (APA):

Herbert-Hansen, Z. N. L., \& Rasmussen, L. B. (2016). Mentorship of expatriates in transnational companies. Journal of Global Mobility, 4(2), 176-201. https://doi.org/10.1108/JGM-05-2015-0018

\section{General rights}

Copyright and moral rights for the publications made accessible in the public portal are retained by the authors and/or other copyright owners and it is a condition of accessing publications that users recognise and abide by the legal requirements associated with these rights.

- Users may download and print one copy of any publication from the public portal for the purpose of private study or research.

- You may not further distribute the material or use it for any profit-making activity or commercial gain

- You may freely distribute the URL identifying the publication in the public portal

If you believe that this document breaches copyright please contact us providing details, and we will remove access to the work immediately and investigate your claim. 
To cite the published article:

Zaza Nadja Lee Hansen Lauge Baungaard Rasmussen, (2016),"Mentorship of expatriates in transnational companies", Journal of Global Mobility, Vol. 4 Iss 2 pp. 176 - 201

Mentorship of expatriates in Transnational Companies

Zaza Nadja Lee Hansen \& Lauge Baungaard Rasmussen

\begin{abstract}
As consequence of the rapid growth of globalization, employees are more likely to be involved in the international activities of their company, with an increasing possibility of being relocated abroad for a certain period of time during their career. A growing body of studies proves an increased interest in the expatriates' experiences, and the main factors that could influence the outcomes of the period abroad as a whole. The aim of the present study is to analyse the roles that mentorship can assume to support and facilitate expatriates. In order to fulfil this aim case studies with three Danish companies were carried out.

This research suggests that informal mentoring is, to some extent, more appropriate when handling personal matters. However, the importance of formal mentoring emerged as well, in order to support mentors and promote knowledge sharing. Therefore, by establishing parallel mentorship realities (formal and informal) within the organization, companies could achieve a higher level of perceived satisfaction of the expatriate's overall experience and, at the same time, ensure that the information accumulated will enrich not only the network-knowledge, but also the organizationalknowledge.
\end{abstract}

Keywords: Mentoring, Expatriate, Coping Strategies, Sense Giving.

\title{
1. Introduction
}

Expatriates in the private sector, as well as within research institutions, have gained increasing attention in recent years, with a focus on both the advances of employing expatriates and the related challenges (Zhuang et al., 2013; Trembath, 2015; Templer 2010). In literature, expatriates are defined as employees who are sent on an extended work assignment in another country (Cooper, 2011; Littrell, 2007). Expatriates are often highly qualified experts in their field, and they are sent on high profile assignments abroad. Expatriates are hired for a number of reasons, including setting up a new operation, training local staff, fulfilling a position the company does not believe local staff can fulfil and finally, to give potential top-managers international experience, as part of their career development (Tungli and Peiperl, 2009; Collings et al., 2007; Feitosa et al., 2014). 
In some transnational companies, expatriates are seen as the most efficient way to transfer the company's critical knowledge to its subsidiaries. In fact, expatriates possess knowledge of the organisational culture and routines, as well as technical knowledge (Graf, 2004).

Expatriation can present many challenges throughout the whole process, for both the organisation and the expatriate: selection and preparation, adjustment to the host country and repatriation. As a consequence the expatriate failure rates are high, and the organisational costs - as well as personal costs for the expatriate him/herself - related to expatriate failure is substantial (Cerdin and Selmer 2014; Selmer and Lauring, 2011; Littrell, 2007; Jassawalla et al., 2006). Therefore there has been a growing focus on the possible benefits of mentoring, defined as one-to-one relationships between an experienced mentor and a less experienced mentee (Cooper, 2011; Littrell, 2007; Jassawalla et al., 2006; Sullivan et al., 2005; Feldman et al., 1999; Harvey et al., 1999; Dirsmith and Covaleski, 1985; Kram, 1983; Kram and Isabella, 1985; Hunt and Michael, 1983). The purpose of this paper is to analyse the different roles of mentoring, and how these roles can be conducted by different types of mentors. The research question is, "What roles do mentors play in the expatriation process and how can these roles help improve the likelihood of a successful expatriation period for both the organization and the expatriate?”

This paper starts with a literature review, followed by data collection and empirical findings of expatriation and mentoring conditions in three Danish multinational organisations. Hereafter, the theoretical and practical implications are outlined, followed by the conclusion and notes for further research.

\section{Literature review}

This section starts with a brief introduction to the concept of coping, and the different strategies that can be implemented to handle change. The mentor figure is introduced immediately after. Different links between mentorship and coping strategies are discussed. The argument is hereafter expanded to the concept of managing expatriates in an organizational context, through mentorship.

\subsection{Coping strategies}

People adapt to change, and manage to identify personal benefits from adverse situations by establishing coping mechanisms (Rotondo et al., 2003). Lazarus and Folkman (1984) defined coping mechanisms as a dynamic effort, in cognitive and behavioural terms, which is used by people in order to face, and eventually overcome, internal or external difficulties that appear to exceed the person's resources. They highlighted two main categories of coping strategies. On one side are emotional-focus strategies which are when the individual tries to make sense out of a situation by changing the meaning of the events. On the other side are problem-focused strategies which are when the individual overcome the issue by trying to change the surrounding environment (Demir et al, 2013). From an expatriate perspective several studies (Stahl and Caligiuri, 2005; Black, 1998; Black et al, 1991) have indicated three different dimensions of adjustment when approaching a different culture: adjustment to work, adjustment to interacting with locals and, on a more general level, adjustment to the local society. Therefore, the expatriate uses coping strategies 
to reduce, manage and eventually overcome, the differences and conflicts they experience during the expatriation period. It is important to keep in mind that, even if coping strategies are selfinitiated, their effectiveness can vary greatly depending on the situation and the culture of the host environment (Aldwin, 1994).

Few studies have analysed the correlation between coping strategies and the adjustment process of expatriates. However, findings seem to indicate a substantial link between these two concepts. Effective coping strategies can play an important role in adjusting to the host-country (Stahl and Caligiuri, 2005).

\subsubsection{Problem-focused and Emotional-focused coping strategies}

Problem-focused coping strategies aim to overcome individual-environmental issues by addressing the problem at its roots, trying to solve the problem by changing the situation. An example would be an expatriate who asks his neighbour for advice because he does not know where to buy groceries (Stahl and Caligiuri, 2005; Lazarus and Folkman, 1984; Lazarus and Launier, 1987; Selmer, 2002; Folkman et al, 1986). On the other hand emotional-focused coping strategies aim to manage the emotions that come as a consequence of the problem itself. An example could be an expatriate who withdraws into the expatriate enclave, because he feels uncomfortable interacting with new host nationals at work and privately. Emotion-focused-strategies could provide more support when the expatriate are unable to actively influence their environment because they are facing major cultural differences (Stahl and Caligiuri, 2005). In these circumstances, the expatriate tries to minimize the anxiety through disassociation from the problem.

Within these two types of coping strategies it is possible to find a wide set of complex and unique coping techniques (Selmer, 2002; Stahl and Caligiuri, 2005; Folkman et al, 1986; Lazarus, 1980; Lazarus and Folkman, 1984). It should be noted that expatriate research has identified two other relevant coping strategies at the individual level (Mäkelä and Suutari, 2011; Pienaar, 2008). Avoidance coping reflects the behaviour of a person when moving away from a stressful situation either physically or psychologically. It can be a temporary or permanent strategy (Pienaar, 2008;

Pienaar and Rothman, 2003). Reappraisal coping refers to the behaviour of a person when making further appraisal of a situation, based on past experiences (Aldwin, 2007).

It is impossible to establish a preference for one coping strategy over another, because the effectiveness of those is tightly related to the assignment context. However, mentorship could be used as tool in order to assist and facilitate the development of healthy and successful coping strategies according to the specific circumstances.

\subsection{Areas and roles of mentoring}

A mentor is defined as a person with advanced experience in his/her operating sector. The role is based on the idea of preparing the protégé (a person with less experience) on how to handle upcoming challenges (Harvey et al, 1999, Kram, 1985). Mentors take a personal interest in the career of the mentee and provides upward organizational mobility and personal growth to him or her. This can be done through coaching and supporting and guiding them in skill development (for 
example technical, interpersonal or political skills) (Hunt and Michael, 1983; Kram, 1985; Mullen, 1994). Research focused on national mentoring suggests that mentors can provide careerdeveloping help (e.g. coaching, sponsoring, protecting mentees from adverse forces and fostering positive visibility), take on psychosocial roles (e.g. personal support, friendship, acceptance, counselling) and serve as role models (Dirsmith and Covaleski, 1985; Kram, 1985; Scandura, 1992). The mentor is not required to fulfil all of these functions to be successful in the role. It is possible to find a great deal of differentiation in regard to the extent of involvement that occurs within different mentoring relationships (Ragins \& Cotton, 1999). Nevertheless, mentorship can be seen as a specific type of coping strategy, which is social in nature, as it always involves two people working together. At the same time, mentorship can be seen as a possible first step towards creating coping strategies as those detailed above.

\subsubsection{Motivation for mentoring}

The reasons for being a mentor can differ between individuals. One of the most documented reasons for being a mentor is related to previous experiences in this context. Different studies have found a positive correlation between the wiliness to engage in mentoring, and the individual's background as a mentor or a mentee (Allen, 2003; Allen, Poteet, \& Burroughs, 1997; Allen, Poteet, Russel et al., 1997; Bozionelos, 2004; Ragins \& Cotton, 1993; Ragins \& Scandura, 1999). Specifically, it seems that, protégés who have experienced a positive outcome from a relationship with a mentor are more incline to reciprocate the help they obtained, becoming mentors themselves (Allen, Poteet, \& Burroughs, 1997).

\subsubsection{Formal and Informal mentoring}

A mentor-mentee relationship can be defined as formal or informal, depending on its nature.

Typically, informal mentorship develops in a spontaneous way. In contrast, formal relationships are built within the organization, most likely through the HR department. Formal relationships seem to be characterized by a shorter life when compared to informal ones (Ragins \& Cotton, 1999; Douglas, 1997). Informal relationships are found to last up to 6 years, while on the formal ones are generally confined to a 12 months period. Informal relationships emerge on the basis of a mutual positive match of the needs that the mentor and mentee intend to satisfy through this interaction. This implies that interpersonal comfort between the parties is taken into consideration (Ragins \& Cotton, 1999; Allen, Poteet, \& Burroughts, 1997; Kalbfleisch \& Davies, 1993; Kram, 1983, 1985; Olian et al, 1993; Olian et al, 1988). While, on the other hand, formal relationships are established by a third party, and mentor and mentee are matched only considering professional factors (Ragins \& Cotton, 1999; Douglas, 1997; Gaskill, 1993; Murray, 1991). Therefore, it is reasonable to expect that in this case, the psychological functions might not be as strong as they could be in an informal context. There are few studies related to the different outcomes between formal and informal mentorship. However, a research carried out by Ragins and Cotton (1999), highlighted different points of interest in this context. The data collected gave substance to the hypostasis that informal relationships were characterized by more intense psychological functions. Moreover, the mentees 
reported more satisfaction with the relationship overall, compared to those in contact with a formal mentor.

\subsubsection{Phases of Mentorship}

In the national area, mentoring has been shown to be multi-dimensional and take on different forms depending on the mentor's level of commitment: 1) professional, 2) relational and 3) personal (Harvey et al., 1999). The first level of commitment, defined as professional, represent a standard level of interaction that characterize formal relationship between managers and their subordinates. The second level of commitment, defined as relational, describe a relationship that is very similar to the ones that can be found at the professional level. However, in this case, the interactions are not limited to direct subordinates. All the employees that need support, and/or can benefit from the manager's expertise and advice, will contact him or her. The third and last level of commitment, defined as personal, takes the communication at a more informal and personal level. With this further step, the organisational requirements are not at the basis of the interaction anymore. The mentor can in each of these levels assume a different role; informational, network, and/or a social role.

To conclude, mentorship has been proved to have a positive impact on a number of factors, like increased job satisfaction for both parties (Koberg et al, 1994), organizational socialization (Ostroff \& Kozlowski, 1993), career commitment and a decrease of turnover intentions (Harvey et al., 1999; Bachman and Gregory, 1993; Viator \& Scandura, 1991). More and more organizations recognize the important role of mentorship and have established formal mentoring programs (Ragins \& Cotton, 1999; Burke \& McKeen, 1989; Geiger-DuMound \& Boyle, 1995; Zey, 1985).

\subsection{International mentorship}

International mentoring is based on the idea that the expatriate - independently from the organizational level to which they belong - will need help to cope and make sense of the new customs and rules that characterize the host environment. Research suggests that mentors play an important role not only in introducing the mentee to the new working position, but also in facilitating their adjustment to the local national culture (Feldman and Bolino, 1999; Black, 1992; Black and Gregersen, 1991; Black et al, 1991). Therefore, the aim of global mentorship is to ensure assistance to the expatriate, in the development of cognitive, adaptive, and affective attitudes in relation to the host country - in terms of both cultural and organizational environments.

In recent years the role of mentoring, in relationship to expatriates, has gained increased attention (see, for example, Cooper, 2011; Littrell, 2007; Jassawalla et al., 2006; Sullivan et al., 2005;

Feldman et al., 1999; Zhuang et al., 2013). Research has shown that effective mentoring can help to minimise some of the challenges with expatriation, but also that few companies use mentoring in international assignments (Jassawalla et al., 2006; Crocitto et. al., 2008; Harvey et al., 1999). As mentorship helps in the process of contextualizing, understanding and weighting the information so that the expatriate will not interpret surroundings erroneously (Harvey et al, 1999; Louis, 1980), it plays a fundamental role in the development of the coping strategies introduced in section 2.1. The 
mentor will provide insights, resources and positive stimuli to encourage efficacious coping (Bandura, 1995). Littrell (2007) found in her study that “... it is the quality of mentoring functions that the expatriate receives from either their mentors, or other individuals who provide career development and psychosocial support, that is most strongly related to positive expatriate outcomes.” (Littrell, 2007:94).

It is valuable to mention how mentorship brings benefits also to the company, and not only to the expatriate. Effective mentorship takes steps to ensure a more ready and reactive representative of the company. This will help to maintain a good reputation and imagine of the home organization at the subsidiary.

\subsubsection{Mentorship and sense making}

Sense making is an important process in which the expatriate develops informative explanations regarding the host environment (Harvey et al., 1999; Weick, 1979). With the perspective of being introduced to a new country, characterized by a high rate of cultural differences, expatriates need to understand how to read others and situations, and how to express themselves when confronting the locals (Harvey et al., 1999; Weick, 1995). The expatriate will need to take steps in order to solve, or at least to reduce, uncertainties.

\subsubsection{Phases of Mentorship}

Exactly like regular mentorship, international mentorship is characterized by different phases that follow the expatriate experience. Harvey et al. (1999) view mentoring as an on-going socialization process, which extends throughout the phases of pre-expatriation, expatriation and repatriation.

The pre-expatriation phase is an initiation phase. The mentor drives the mentee through a wide range of potential situations and issues that could occur upon his/her acceptance of position abroad. Another important challenge is to align the future expatriate's expectations for the overseas assignment with reality. Furthermore, the pre-expatriation phase is essential in terms of sense making (Harvey et al., 1999).

During the expatriation experience the mentor helps the mentee to overcome issues that being abroad brings with it, and to make sense out of social and organizational behaviours (Harvey et al, 1999; Weick 1995). In order to facilitate the effectiveness of this phase, it is fundamental that the pre-expatriation phase manages to establish a solid mentor-mentee relationship. In this way communication issues caused by the long distance, will have a smaller impact on the relationship itself (Harvey et al., 1999).

In the post-expatriation phase, the mentor assumes the role of bridge between the organization and the mentee. The aim is to facilitate the re-integration of the expatriate back into the original work environment, with a plan to further his/her career (Feldman and Bolino, 1999; Feldman, 1991; Feldman and Thomas, 1992; Feldman and Thompson, 1993). In this phase the mentor should make sure that the knowledge gained by the mentee's experience abroad becomes part of the organizational culture. By doing so the future generations of expatriates will have the chance to get 
more insights and make sense out of the expatriate's adventure. This should imply a future increase of the competencies and the impact that expatriates will bring to the subsidiary's intellectual capital (Harvey et al, 1999; Harvey and Wiese 1998).

\subsubsection{On- and off-site mentoring}

Schein (1979) underlined how expatriates may encounter different level of resistance at their arrival to the subsidiary, depending on the local culture and mind-set. Different societies are in fact characterized by different levels of ethnocentrism (Axelrod, and Hammond; 2003), openness to foreigners, and wiliness to trust outsiders. In situations in which the host country is known for being stricter and more individualistic, the presence of an on-site mentor might facilitate overcoming this resistance. This is a very delicate issue because the extent to which expatriates feel successfully socialized play a determinant role on the perceived satisfaction of the expatriate experience overall (Feldman and Bolino, 1999; Guzzo, 1993).

Mezias and Scandura (2005) found that according to the different stages of their experience abroad, expatriates will face different development and adjustment issues. Each one of these issues might be more effectively handled by the expatriate with the help of different type of mentors. Scholars of global mentoring distinguish between two sources of mentors for expatriates, the host country and the home country (Zhuang et al, 2013; Mezias and Scandura, 2005; Jassawalla et al, 2006). Home country mentors are when a mentor has knowledge about the specific host country, often due to a personal previous experience. The concept behind host country mentors are the same, but in this case the mentor is a local, who has knowledge and resources that could help the expatriate with his or her adjustment process (Zhuang et al, 2013; Mezias and Scandura, 2005; Jassawalla et al, 2006). On-site mentoring has different advantages that are only partially covered by home mentorship, and it might turn the expatriate experience into a more effective and efficient one. In fact, not only is a host-based mentor familiar with the local culture and customs, but he/her is going to work with the mentee on a daily base, which will give a better understanding of which kind of issues the mentee is facing in his/her everyday working life. However, a down side can be that the on-site mentor might not be as sensitive as a mentor from the home country to the adjustment difficulties. In fact, the home mentor, because of his/her experience, is probably more aware of the cultural differences the mentee could encounter, while the host mentors might fail to actively inform the expatriate, because their local identities could make them take such everyday life experiences for granted.

To summarize, international mentorship has the potential to be turned into a power tool of social facilitation in companies that operates on a global scale, with implications for numerous organizational outcomes - such as turnover and reputation (Harvey et al, 1999).

\subsection{Summery}

The literature review illustrates how mentorship has been proved to have a positive impact on all the involved parties to various degrees: the organization, the mentee, and the mentor. The mentor has enough power to influence the mentee's development of healthy coping strategies by giving advice and assistance through the different stages of the mentee's experience abroad. Even though 
the role of mentoring expatriates is a young research area, the studies carried out until now seem to agree on the potential for mentorship in these circumstances. Two key different natures of mentoring has been investigated in literature; formal and informal. Both types of mentoring have been shown to be effective to different degrees and in different situations. In other words then mentoring is an important aspect to investigate in order to understand why some expatriate assignments fail while others become a successful experience for both the expatriate and the organisation.

\section{Data collection}

The nature of the research questions suggested a case-study approach, due to their explorative nature wherein unknown factors and elements are sought (Yin, 1994). Multiple case studies were used to make comparisons, and to distance the researcher (Eisenhardt, 1988). This method allows for exploration of the topic and can help provide new insight. Such methodology is used for discovery, not for generalization, as this paper addresses a largely unexplored area in literature.

A multi-case study approach was taken to investigate three Danish companies, in similar industries, and considering one host-country context - China. The company X1 was assessed as an in-depth case while companies X2 and X3 were used to validate the results. The case companies were selected based on a number of criteria; (i) they were large international organizations, with headquarters and ownership in Denmark, (ii) they had Danish engineers stationed in China, (iii) the companies' expatriates were there to transfer technical knowledge to Chinese engineers in the subsidiaries, and were either experts, project managers or both and (iv) the companies had expressed problems with expatriation, and a wish to improve this situation with the help of this study.

In X1, it was possible to interview Danes expatriated to China, former expatriates now in Denmark, HR managers in the headquarters and top managers in the headquarters. In X2, interviews were carried out with expatriates in China and top managers and HR managers in the headquarters. In $\mathrm{X} 3$, interviews were carried out with expatriates in China. All the companies had expatriates in other locations but the focus of this study was on expatriates in China. X1 had all its research in Denmark but the majority of development work had been offshored to China. X2 had offshored almost all of the engineering work to an Indian subsidiary, but R\&D was divided between USA, Denmark and India. Work in China was mainly with clients and suppliers. X3 had offshored part of product development to China for local and global markets.

Table 1 shows the case companies with regard to type of company, subsidiaries locations, subsidiaries roles, the position of the interviewees and the number of interviewees.

\section{[INSERT TABLE 1]}

Participants were found through expatriate organizations and with the help of the Danish interest group Danish Industry (DI), which most Danish companies are members of, as well as The Danish Society of Engineers (IDA), as the industrial context meant that the majority of expatriates were engineers by trade. Both of these organisations advertised our study on their website. Participants 
also introduced us to some of their contacts in their networks, and this snowballing sampling helped to expand the study.

Thirty-seven interviews were conducted with expatriates, managers and vice presidents who managed different aspects of interaction with expatriates in the headquarters and in the subsidiary. In this manner both mentors and mentees were investigated and both organisational and expatriate viewpoints were gained on the use and benefits of mentoring networks. Different numbers of interviewers were conducted within the three companies to ensure the amount of expatriates sent out to a given country at the same time would not be an influencing factor on the results.

Almost all interviews were conducted face to face, including those with the expatriates in China. However, due to practicality, a few interviews were conducted over the phone or when the expatriates were in Denmark, either permanently (repatriated) or on an assignment. By interviewing employees from both the corporate headquarters and the subsidiaries, a multifaceted perspective was gained.

All expatriates were Danish males, between 30 and 45 years old, expatriated to China with their families (spouses, and in some cases children), for an average length of 2 years. They were all expatriated to similar positions, and with similar areas of responsibility. In the selection process, interviewees were selected so these outside influencing factors were similar and therefore could be ignored, permitting focus of the research to be on the role of the expatriates within these boundary conditions.

The primary data sources were semi-structured interviews, where structured questions were asked but the interview was open for new information. All the interviews lasted 50-70 minutes, were audio-recorded and transcribed. The interview guide had five topics to ensure the main aspects were covered. These were; the interviewee's experience of the expatriation process (moving out), adjustment, repatriation (if appropriate), mentoring and other aids to help adjustment and perceived satisfaction with the expatriate experience.

The transcribed interviews were coded and analysed using meaning categorization and meaning interpretation (Kvale, 1996). These approaches were selected in order to get a clear overview of how general certain views were and how these were connected. To ensure validity of the results, the multiple interpreters' approach was used by having some interview segments analysed by a researcher who was not a part of the study.

Note that the findings for all three case companies were very similar. The in-depth case, X1, will therefore often be used to illustrate a finding in detail.

The companies measured expatriates' success both through the employees' turnover rate after repatriation, and the perceived organisational benefit from the engagement with the assignment overseas. All the companies had experienced problems keeping repatriated expatriates in the company. For example, in X1 in 2009, around 10\% to 20\% of expatriates left X1 after repatriation, whereas the number for previous years was around $20 \%$, some years as high as $50 \%$. The change is likely due to X1 resolving practical issues in expatriation and the global financial crisis, which 
made it harder to change jobs. In X1, expatriates who came from ordinary (specialist) positions and who were sent to managerial positions in China kept their previous job status when they returned. This led to dissatisfaction and unmet expectations of job advancement, which were often reasons for leaving the company.

The expatriates gained knowledge in several areas, a large part of which were soft skills or managerial skills. HR managers in the three companies knew that the expatriates gained professional competences, managerial skills, knowledge of how to navigate in a smaller organisation, broader understanding of the world and international perspective. However, there were no procedures, processes or mechanisms in place for the expatriates to transfer their knowledge to the home organization.

Knowledge sharing in X1, X2 and X3 was unilateral, namely from the headquarters to the offshored location. Thus, the main knowledge flow was "top-down" through training, development and coaching of Chinese employees in methods and standards used in the headquarters. At the same time, the headquarters did not pay attention to the fact that the company could also learn from their foreign colleagues, the Chinese colleagues in particular. This was illustrated by a top manager in X1 who said, "They [in China] gained a lot of training [...]. We have not had the possibility to get much in return. But that is our fault here in Denmark, certainly our fault."

The majority of the Danish employees at the three companies felt that the Chinese office could not be used in other instances than purely cost cutting goals, as illustrated by one of the HR representatives: "One of the challenges in regards to the cultural issues in our company is overall prejudgment of each other based on cultural backgrounds. [...] for example [...] we look upon Chinese work [...] differently than we look on our Danish and US' colleagues work. We think it is not the same standard as we have. That is the prejudice we have to their work."

\section{Mentoring}

The three case companies provided varied examples of informal expatriate mentoring, which will now be discussed. In company X1, a woman, here named Mary, had become the unofficial mentor for all of the company's expatriates to China. She had been expatriated to China twice, and had been among the first Danish expatriates to China in the early 1990s. In her current position in the Danish headquarters, she travels regularly to China. Her role had emerged over the years, and she had been an informal contact point for the expatriates during her own stays in China. She had organized several social events, helped with practical concerns (like where to buy certain items), listened to personal problems (like strain in the family, loneliness and isolation caused by the expatriation) and professional concerns and issues (like how to work with/lead Chinese employees, and how to communicate with the headquarters) as well as career-related concerns (how to use the expatriation stay to advance one's career, and how to stay connected to the headquarters). Mary was very well connected and had a good reputation among her peers, a person whom the people interviewed in X1 knew well. Mary has been described as a very emphatic person, and a good listener. She was good at creating networks and she had a good understanding of cultures and communication. One of the interviewed expatriates said of Mary, "We would have been lost when 
we first arrived without her," while another said, "She helped us [the expatriate and his family] adjust... I'm not sure we would have stayed otherwise." A third expatriate mentioned the value of talking confidentially to her, saying, "I could tell her anything.... She was always easy to reach.”

Despite having advanced from a technical engineer position to a managerial and project management position, Mary maintained her network and still had the time, desire and energy to be the contact person and mentor of expatriates to China and repatriates to Denmark. She herself said that she liked doing this type of work even though it was not recognized or rewarded by the organization. She said that she was able to find the time for this informal mentoring partly because she had no children of her own. However, she felt that some support from the company would make it easier for her to help, guide and advice people. Many of the expatriates in China felt that being mentored by Mary had made their expatriation and repatriation periods easier and more successful, viewed both from professional and personal perspectives. She kept them updated and connected, making it easier for them to be remembered in the home organisation, when they were expatriated. However, as the number of expatriates to China had increased, Mary felt that she could no longer be so intensively in touch with everyone as she used to be, and she expressed a desire for someone to share the role with.

In X2 and X3 the unofficial mentor role was not executed by one particular person. Several people were involved in mentoring the expatriates. Therefore, the expatriates often spoke with different people depending on what issues they wanted advice on (e.g. professional, personal, practical advice). These mentors were in general less qualified in the organizational hierarchy, which made them less able to help regarding professional issues. However, like Mary, they had all been expatriated to China, and engaged in mentoring despite the fact that they were unsupported by their companies. They did so because they wanted to. They arranged social events, both while abroad and in Denmark. Finally, like Mary, they were reported to be very empathic and good listeners.

The following table show examples from each type of mentoring relationship from the three companies, using the categories defined by Harvey et al. (1999) for domestic mentoring.

\section{[INSERT TABLE 2]}

As mentioned in literature review, the engagement of a mentor in relation to a mentee can vary on a quite wide scale. The framework is based on a multi-dimensional approach that underline the different levels of mentor commitment, and the different roles the mentor can undertake within each one of these levels, according to the situation. Some of the data collected during the different interviews has been implemented in the matrix, aiming to induce a more intuitive understanding of the different circumstances that define each dimension. The following statements are all from expatriates, in regards to the relationships established with their mentor.

"He put me in contact with [D] who knew how to handle the transaction." - Professional, Network. The manager acts as a bridge, connecting the mentee with key managers, which can help in handling and solving the difficulties that the employee is experiencing. 
"She told me if I want to know about [X] then I should go talk to [Y]. Even though she actually doesn't have anything to do with it." - Relational, Informational. The mentor gives advice and act as a guide into the informal relations within the organization.

"I could talk with her [my mentor] about my marriage problems." - Personal, Social. This statement highlights how, at this level and at this dimension, the relationship between mentor and mentee is informal and based on affection. The emotional support is not only limited to professional issues, it also include private ones.

However, even though the framework identifies specifications that should help in the classification of the relationships between mentor and mentee, it doesn't mean that this classification is always feasible. In fact, the empirical findings highlighted that only in rare occasions was it possible to find a good match between the framework categories and the relationship qualities. Most of the data are testimonies of the same mentors that cover different roles, depending on the circumstances.

It is valuable to mention how some of the expatriates reported that they received host mentoring while abroad. However, the mentors were not locals, but fellow expatriate colleagues. When dealing with issues related to the company, they would seek advice from other Danish or Western co-workers. To handle difficulties on more general problems related to the expatriation experience, they would take advantage of the advice from the western expatriates' network. Moreover, those who moved overseas with their spouses mentioned how their spouses would meet and support each other in terms of practical everyday matters (like household and kids). Nevertheless, they confirmed that the best connections were those with other expatriates; either those now back in Denmark, or those still in China.

In summary, all the mentors reported that they liked and were willing to continue the mentoring role, but that they needed more support from the home organisation. The mentees reported that they had experienced the mentors to be empathic, good at listening, good at understanding cultural differences, and well integrated in the companies.

\section{Discussion}

The study indicates that the HR departments in the case companies participated in the expatriates' experience only to a very limited extent. The relocation of employees was mainly handled by the expatriate him or herself, with HR providing some selected practical help. The study highlighted how this situation creates discomfort in the employee, who starts looking for information and assistance elsewhere. In response at these circumstances, within the network of expatriates, a selfappointed informal mentor appears. This figure, because of its very nature, is not officially recognized within the company. The wiliness to help colleagues in facing unresolved doubts, fears and issues, is one of the major drivers behind informal mentoring in the case companies. The informal mentoring is done mostly on a voluntary basis, and survives due to the personal interest of the mentor in helping other less-experienced expatriates. The same findings are reported by Cooper 
(2011). To conclude, it was shown that mentors played a fundamental role in the expatriate experience, especially in terms of adjustment to the local culture and work environment.

The informal system that characterizes the expatriate's mentorship experience presents both pros and cons. On a personal level, it easier for the employees to create a bond of trust with the mentor. The mentor typically takes this call because of his/her previous involvement in a similar situation (e.g. Mary, who was previously deployed twice to China). The mentor's experience created a solid background and knowledge at a personal level, and mentoring is the way through which this knowledge is shared. However, it is possible that the unofficial mentoring could have been a reason for the low involvement of HR; and it is important to consider that, it may not be a good idea simply to expect HR in the home organisation to take over all mentoring tasks. Partly because the expatriates may not be willing to discuss sensitive personal experiences with them for the sake of their on-going career, and partly because HR in the home organisation is, in many cases, filled with people who have not themselves been expatriated to the site in question, and therefore do not understand the cultural context in which the expatriate must work, live and interact in practice.

On the other hand, unofficial mentoring means that knowledge sharing is limited and not recorded; therefore the organizational knowledge that emerge by all the personal experiences of the different expatriates is not embedded into the organization. The combination of the increasing number of foreign assignments, and the non-recognized voluntary role, do not create easy circumstances for the mentors. They express a wiliness to keep engaging with expatriates, but complained that there was a lack of time and assistance in doing so. Another weakness of the voluntary mentoring system running in the three companies lies on its high dependence on a few individuals. In fact, the system works only as long as the self-proclaimed mentors are able and willing to cover such role.

Mentoring is not an easy task, and can be very demanding in terms of both time and energy. This could cause a step-back for the mentor, who could find him or herself in the position of not being able to fulfil the role anymore, or maybe only to a limited extent.

In conclusion, it can be seen that expatriates gain useful knowledge while they are abroad but there is a substantial lack of official channels to transfer and integrate it into the home-organization.

\section{Theoretical and practical implications}

The following sections illustrate the theoretical and practical implications of this research study.

\subsection{Theoretical Implications}

Inspired by the literature review and by the empirical study, this paper suggests that mentoring can be divided into the types and areas showed in Table 3 . The areas of mentoring were selected based on what the interviewed expatriates mentioned they had benefited from, and what they would have liked to receive mentoring on. The domains were also selected based on which areas have been found to be most difficult for expatriates in previous studies in this regard, as illustrated in the literature review.

[INSERT TABLE 3] 
The areas of mentoring are divided into issues related to different aspects: 1 ) work culture in hostorganisations, 2) culture in the host-country, 3) ethnocentrism in home-organisations and 4) family and personal issues. The types of guidance are divided into a) informal and formal rules, b) networks, and c) mediation of conflicts and/or crises.

Types of mentoring in relation to work culture in the host-organisation include information about formal and informal rules communicated both in the pre-expatriation phase and during the beginning of the expatriation experience. This type of mentoring can be provided by special introduction courses, or workshops arranged by either experienced people in the host-organisation, or by an informal mentor, supported by the HR department, in the home-organisation. Particular emphasis should be put on the rules of the host-organization that differ from the home-organisation, as well as what could happen if these rules are not followed. If some of the host-rules are working inappropriately, it could also be discussed how the expatriates might try to explicitly or implicitly change them, and the possible positive and negative outcomes of this. In the empirical study informal mentors conducted this type of mentoring. However, if this part had been handled by the HR department it is likely this would have given the informal mentor more time to focus on more complex types of mentoring.

A second type of mentoring in relation to the work culture is network building. It creates the basis for helping the expatriates understand what the most appropriate strategies are to create a productive and informative network within the host-organization. Such networks are really important because they play a key role in helping the expatriate in receiving information and getting them assistance through the different stages of his/her experience, particularly when facing challenging tasks, or dealing with undesirable/surprising events. These networks are also essential for the expatriates to communicate to the local staff why, and how, they want to make changes in the procedures and behaviours of the host-organisation (Shen and Kram, 2011). It is important that this type of mentorship is provided by a person that has direct experience with the host-organization. Network mentoring should be focused during the pre-expatriation phase, up to the first period of the experience overseas.

A third type of mentoring in relation to work culture is related to mediation of work-related conflicts (e.g. violation of informal or formal rules, or power relationships). It could be mediated by an experienced person in the host-organisation, or by an informal mentor with knowledge about the work culture in the host-environment. In our empirical study, it was the informal mentor that covered this area and type of mentoring.

Types of mentoring in relation to the culture of the host-country include information about the formal and informal rules characterizing the culture in the host-country. Such rules could, for instance, be about showing respect for religious rites, ways of making contacts to local people, proper behaviour in public spaces, ways of talking or writing to people in the host-country, and how to behave in different formal and informal situations. Some of this knowledge could be communicated through written procedures and preparatory courses in the pre-expatriate phase, by persons who have stayed, experienced, and lived in the host-culture recently, or for a longer period 
(Li-Yueh, 2014). Several of the expatriates interviewed in our study, mentioned that they used the networks in the host-country to obtain this type of mentoring.

Another type of cultural mentoring is guidance to establish informal relationships in the local community (Zhuang et al., 2013). This is, of course, closely related to the recognition of the formal and informal rules of communication and behaviour mentioned above. This type of mentoring could be provided by an informal mentor, or by other expatriates who have stayed for some time in the host-country.

A third type of cultural mentoring is mediation of culture-related conflicts. What should the expatriate do if a misunderstanding, or a deliberate conflict, occurs? This is probably best mentored by an informal mentor, experienced in dealing with such types of conflicts. In our study Mary reported that she had conducted this type of mentoring several times.

Types of mentoring in relation to ethnocentrism in the home-organisation include informal coaching on how to communicate with the headquarters in the home country. Ethnocentrism is defined as the belief that one's own culture is superior to others, and represent the standard by which all other cultures should be measured (Axelrod, and Hammond; 2003). Ethnocentrism was mentioned by several of the persons interviewed in this study. Often the employees of the headquarters' HR department are not experienced with the host-cultures of the expatriates. In order to hide their ignorance, or due to an ethnocentric attitude, HR employees can cling to a way of thinking and doing things in their home-organisation, even if the expatriates try to convince the HR employees that the suggested procedure would not work abroad. The dilemma experienced by some expatriates is how to cope with different kinds of ethnocentrism, without being blamed for not following the "business-as-usual" way of behaving in the home-organisation. In such situations, guidance from an informal mentor who has experienced the same kind of issues first hand may turn out to be more valuable for the expatriate, than endless and most likely disappointing discussions with the HR department in the headquarters.

A third type of mentoring related to ethnocentrism is guidance of ethnocentric conflicts or disagreements, when they occur. A conflict might occur, for instance, when an expatriate identifies a practical solution to managing a production site in a different way than what the standards of the headquarters prescribe. An informal mentor could help in mediating a solution, if she/he has the appropriate experience, empathy and negotiation skills. In this study some expatriates mentioned how they attempted to force the local staff to strictly follow the standards of the headquarters, only to find the local workforce was not enthusiastic about doing so. This situation may create a 'hidden' conflict because the local staff may fear the consequences of disagreeing with the expatriate. Ethnocentrism can be grounded in the attitudes of the local staff, the expatriated individuals or in the employees in the home-organisation.

The last area of mentoring includes family and personal issues. The data collected highlighted how several expatriates seemed to prefer informal mentoring to support them in matters covering practical help in the host-country, guidance in relation to family problems and advice on personal crises during the expatriation. 


\subsection{Practical Implications}

Based on the findings from the case studies and the conducted analysis it is recommended that a company seeking to gain full advantage of a mentor-mentee relationship for expatriates consider the following:

\section{Establishment of a formal mentoring programme}

The analysis emphasizes how managing expatriates uniquely through informal mentorship can result in an overwhelming workload for the informal mentors. Having formal mentors, running side by side with their informal colleagues, would provide assistance and make time for the informal mentors to focus on more delicate and complicated mentoring aspects. For example Mary could manage to keep direct contact with all the expatriates if she was not the only reference point for the whole group. The introduction of formal mentoring programmes would also help in strengthening the organizational knowledge. The reports collected consequently to mentor-mentee meetings could be analysed and used to create frameworks and ready-answers, which could consequentially be used to reduce the mentee's dependence on the appointed formal mentor's knowledge and abilities (Harvey et al, 1999; Harvey and Wiese, 1998). This would go in support of the three dimensions of mentoring in relation to the culture of the host-country, and in relation to ethnocentrism issues. The suggested approach could lead the home-organization to establish a defined behavioural path that incorporates acceptable social behaviours and a much wider general understanding of the hostenvironment. Last but not least, the introduction of a formal mentoring programme, and the recognition and support of the informal mentorship system, could also help to address the turnover problem X1 have been experiencing. As the literature suggests, once the expatriate assignment is about to expire, and the employee is getting ready to re-enter the country, the mentor can help in facilitating the re-integration of the repatriate into the home-organization, helping to find an available position that reflects the new professional level reached during the employee's overseas experience (Feldman and Bolino, 1999; Feldman, 1999; Feldman and Thompson, 1993; Feldman and Thompson, 1992).

\section{Introduction of hiring policies to ensure HR staff capabilities}

The introduction of new recruitment policies when hiring HR team members could help in creating the basis knowledge required to involve the HR department in the mentoring process in a more efficient and productive way. These new policies should ensure variety within the team, guaranteeing that at least part of the group has experience with expatriation and repatriation in general, and possibly also direct experience with the countries with which the company sends most expatriates.

\section{Rewards for mentors that made a difference to an expatriate's experience abroad}

Based on the findings from the case studies it seems reasonable to assume that the recognition of the mentor's role might turn into a motivational trigger, pushing more former expatriates into covering such a role. This, in the case of company X1 for example, would probably make it easier for the organization, to find volunteers that can physically sustain Mary’s work. Motivated both by 
the respect and the good memory of Mary's influence, and by seeing the company's recognition to her, more former expatriates might decide to engage in mentoring activities. The same concept would work when applied to companies X2, and X3.

To summarize, this study has shown that mentoring is an important sub-area of coping- a concept that can be defined as largely unexplored in literature. At the root of the mentorship concept one finds someone who has been in a similar stressful situation and offers his/her knowledge to help inexperienced colleagues. The suggestions received can aid and assist the expatriate to develop constructive coping mechanisms during the different stages of his/her experience.

This research shows that mentorship is a powerful tool to facilitate the expatriate process. However, the implementation of a formal mentoring program could have helped in providing a more efficient support to the expatriates. Formal mentoring should be organized to sustain and work in parallel to the informal mentoring already in place within the organizations. It is therefore essential to create a successful expatriation period to China that companies give importance and invest in both formal and informal mentoring.

\section{Conclusion}

Expatriation was investigated through three case studies of Danish multinational companies with expatriates in China. The results highlighted a lack of understanding regarding the importance of the different types and areas of mentoring in the HR department of the home-organisations. Often, expatriates try to solve this situation by relying on informal mentoring and networks. In particular, the use of unofficial mentors, who helped with organisational and practical issues, were seen in the case companies as helping to ensure a more successful expatriation period for the expatriate. The multi-dimensional approach of combining various areas and types of mentoring, as shown in Table 3 , indicates that some elements of mentoring is most appropriately conducted by an informal and culturally experienced mentor with personal skills like empathy, active listening, patience and personal motivation to help less experienced expatriated colleagues. In this study, mentors like Mary are able to fulfil all the different types of mentoring discussed in this paper. However, such an informal mentoring process is vulnerable because it depends heavily on a single individual, or relatively few people, who volunteer to offer guidance and support to colleagues, often without recognition and support from the organisation.

By establishing parallel, but not integrated, formal and informal mentoring, expatriates, local employees in foreign subsidiaries and employees in the headquarters can share knowledge, and receive social and emotional support. Such support could take the form of workshops, which discuss the different types of ethnocentrism and methods to overcome the barriers of cross-cultural communication and learning in multi-cultural work groups. Based on the literature review and our studies, it is suggested that the HR department support and/or take care of the introduction courses. At the same time, expatriates should be given the possibility to spontaneously select informal mentors from a group of previously repatriated people, who are willing to be a mentor. These 
people should be known to be empathic, extroverted, trustworthy, experienced in the host-culture and motivated to help expatriated newcomers. The headquarters should then assign the informal mentor time and resources, to hold meetings with expatriates and support them through their journey. It is essential that the organization will not interfere with, or try to get information out of the informal mentors. This would most likely create a trust gap between the informal mentors and their mentees. By officially recognizing and supporting the use of informal mentors and encouraging strong informal networks, organisations can create communities of practice with a high level of knowledge sharing between expatriates, allowing knowledge to be stored in these networks and retained by the organizations (Wenger, 1998).

\section{Notes for further research}

The approach to successful mentoring of expatriates suggested in this paper needs to be tested in more companies. Particularly within companies outside Denmark, with expatriates going to different countries. The relationship between mentorship reputation within the company and the wiliness to engage in an international experience by the company's employees could be another interesting research focus. An employee might be more incline to accept an overseas assignment if he/she has been told by their network, that the company takes all the necessary steps to ensure an easy expatriation/repatriation process. Furthermore, it could be beneficial to investigate how mentoring can best be supported by the organisation and identify what key processes, procedures and approaches need to be integrated in order to use informal mentoring in the most optimal way for the given organization and its employees. It could also be interesting to investigate the boundaries between the unofficial network of mentors and the official HR function and how such parallel approaches can be made most beneficial for the expatriates, as well as for the host- and home-organisations. Finally, future research should focus much more on the expatriate dilemmas created by different types of ethnocentrism either in the home-organisation or in the hostorganisation and how these forms of ethnocentrism can be transformed to cross-cultural understanding and learning.

\section{Reference list}

Aldwin, C. M. (2007), Stress, Coping, and Development: an Integrative Perspective (2nd edition), Guilford, New York, NY.

Allen, T. D. (2003). Mentoring others: A dispositional and motivational approach. Journal of Vocational Behavior, 62, 134-154

Allen, T. D., Poteet, M. L., Russell, J. E. A., \& Dobbins, G. H. (1997). A field study of factors related to supervisors’ willingness to mentor others. Journal of Vocational Behavior, 50, 1-22.

Allen, T. D., Poteet, M. L., \& Burroughs, S. M. (1997). The mentor's perspective: A qualitative inquiry and future research agenda. Journal of Vocational Behavior, 51, 70-89.

Allen, T.D. 2007. Mentoring relationships from the perspective of the mentor. In B. R. Ragins \& K. E. Kram (Eds.), The handbook of mentoring at work: Theory, research, and practice: 123-147. 
Axelrod, R., Hammond, R.A., 2003. The evolution of Ethnocentric Behaviour. Paper prepared for delivery at Midwest Political Science Convention, April 3-6-, 2003, Chicago, IL

Bachman, S.I \& Gregory, K. (1993), Mentor and protégé gender: Effects on mentoring roles and outcomes. Presented for Society for industrial and organizational psychology conference, San Francisco, April.

Black, J.S., Gregersen, H.B. and Mendenhall, M.E. (1992), Global Assignments, Jossey-Bass, San Francisco, CA.

Black, J. S. and Stephens, G. K. (1989), “The influence of the spouse on American expatriate adjustment and intent to stay in Pacific Rim overseas assignments”, Journal of Management, Vol. 15, pp. 529-544.

Bossard, A. and Peterson, R. (2005), “The repatriate experience as seen by American expatriates”, Journal of World Business, Vol. 40 No. 1, pp. 9-28.

Bozionelos, N. (2004). Mentoring provided: Relation to mentor's career success, personality, and mentoring received. Journal of Vocational Behavior, 64, 24-46.

Burt, R.S. (1997), “The contingent value of social capital”, Administrative Society Quarterly, Vol. 42 No. 2, pp. 339365.

Carraher, S.M., Sullivan, S.E. and Crocitto, M.M. (2008), "Mentoring across global boundaries: an empirical examination of home- and host-country mentors on expatriate career outcomes”, Journal of International Business Studies, Vol. 39 No. 8, pp. 1310-1326.

Cerdin, J-L and Selmer, J (2014). Who is a self-initiated expatriate? Towards conceptual clarity of a common notion. The international Journal of Human Resource Management, Vol. 25, No. 9, pp. 1281-1301

Cho, T., Hutchings, K. and Marchant, T. (2013), “Key factors influencing Korean expatriates’ and spouses’ perception of expatriation and repatriation”, International Journal of Human Resource Management, Vol. 24 No. 5, pp. 1051-1075.

Collings, D.G., Scullion, H. and Morley, J.M. (2007), “Changing patterns of global staffing in the multinational enterprise: challenges to the conventional expatriate assignment and emerging alternatives”, Journal of World Business, Vol. 42, pp. 198-213.

Cooper, D.C. (2011), “Crossing cultures: a qualitative study of expatriate experiences with mentors during international assignments”, Unpublished doctoral dissertation, University of Minnesota, Minnesota.

Crocitto, M.M; Sullivan, S. E. \& Carraher, S. M. (2008), "Mentoring across global boundaries: an empirical examination of home- and host-country mentors on expatriate career outcomes”, Journal Of International Business Studies, Vol. 39, No. 8, pp. 1310-1326.

Demir et al, 2013, "Effect of Mentoring Program on Ways of Coping with Stress and locus of Control for Nursing Students”, Asian Nursing Research.

Dirsmith, M.W. and Covaleski M.A. (1985), "Informal communications, nonformal communications and mentoring in public accounting firms”, Journal of Accounting Organizations and Society, Vol. 10 No. 2, pp. 149-169.

Eisenhardt, K.M. (1988), “Agency - and institutional theory explanations: the case of retail sales compensation”, Academy of Management Journal, Vol. 31 No. 3, pp. 488-511.

Feldman, D.C. and Bolino, M.C. (1999), “The impact of on-site mentoring on expatriate socialization: a structural equation modelling approach”, International Journal of Human Resource Management, Vol. 10 No. 1, pp. 54-71.

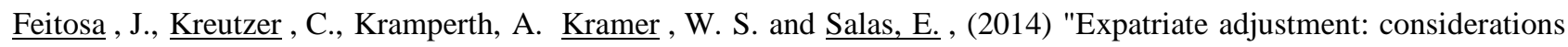
for selection and training", Journal of Global Mobility, Vol. 2 (2), pp.134 - 159

Graf, A. (2004), "Expatriate selection: an empirical study identifying significant skill profiles”, Thunderbird International Business Review, Vol. 46 No. 6, pp. 667-680. 
Hunt, D. M., \& Michael, C. (1983). Mentorship: A career training and development tool. Academy of Management Review, 8, 475-485.

Harvey, M., Buckley, R., Novicevic, M.M. and Wiese, D. (1999), “Mentoring dual-career expatriates: a sense-making and sense-giving social support process”, The International Journal of Human Resource Management, Vol. 10 No. 5, pp. 808-827.

Hemmasi, M. and Downer, M. (2013) "Cultural distance and expatriate adjustment revisited", Journal of Global Mobility: The Home of Expatriate Management Research, Vol. 1 (No. 1), pp.72 - 91.

Hunt, D.M. and Michael, C. (1983), “Mentorship - a career training and development tool”, Academy of Management Review, Vol. 8 No. 3, pp. 475-485

Ismael, A.R., Battour, M.M. and Bhatti, M.A. (2013), "Expatriates adjustment and job performance: an examination of individual and organizational factors”, International Journal of Productivity and Performance Management, Vol. 62 No. 7, pp. 694-717.

Jassawalla, A.R., Nader, A. and Sachittal, H.C. (2006), "Managing expatriates: the role of mentors”, International Journal of Commerce and Management, Vol. 16 No. 2, pp. 130-140.

Koberg, C. S., Boss, R. W., Chappell, D., \& Ringer, R. C. (1994). Correlates and consequences of protege mentoring in a large hospital. Group and Organization Management, Vol.19, pp.219-239.

Kram, K.E. (1983), “Phases of the mentor relationship”, Academy of Management Journal, Vol. 26 No. 4, pp. 608-625.

Kram, K. E. (1985). Improving the mentoring process. Training and Development Journal, Vol.39, pp.40-43.

Kram, K.E. and Isabella, L.A. (1985), “Mentoring alternatives - the role of peer relationships in career-development”, Academy of Management Journal, Vol. 28 No. 1, pp. 110-132.

Kvale, S. (1996), “The 1.000- page questions”, Qualitative Inquiry, Vol. 2 No. 3, pp. 275-284.

Lazarus, R. and Folkman, S. (1984). Stress, Appraisal and Coping, Springer, New York, NY.

Lee, L. and Kartika, N. (2014), “The influence of individual, family, and social factors on expatriate adjustment and performance: the moderating effect of contract and organizational support”, Expert Systems With Applications, Vol. 41 No. 11, pp. 5483-5494.

Littrell, R.F. (2007), “Influences on employee preferences for empowerment practices by the 'ideal manager' in China”, International Journal of Intercultural Relations, Vol. 31 No. 1, pp. 87-110.

Li-Yueh, L., Veasna, S. \& Sukoco, B.M. ( 2014). The antecedents of cultural effectiveness of expatriation: moderating effects of psychological contracts. Asia Pacific Journal of Human Resources, Vol. 52, pp. 215-233

Matthieu and Ivanoff, (2006). "Using Stress, Appraisal, and Coping Theories in Clinical Practice : Assessments of Coping Strategies After Disasters”.

Mäkelä, L. and Suutari, V. (2011), “Coping with work-family conflicts in the global career context”, Thunderbird International Business Review, Vol. 53 No. 3, pp. 365-375.

Mullen, E. (1994), “Framing the mentoring relationship in an information exchange”. Human Resource Management Review; Vol.4, pp.257-281. 
Noe, R.A and Barber, A.E. (1993), "Willingness to accept mobility opportunities: destination makes a difference", Journal of Organizational Behaviour, Vol. 14 No. 2, pp. 159-175.

O'Sullivan, S.L. (2002), “The protean approach to managing repatriate transitions”, International Journal of Manpower, Vol. 23 No. 7, pp. 597-616.

Pienaar, J. (2008), “Skeleton key or siren song: Is coping the answer to balancing work and well-being?” in Näswall, K., Hellgren, J. and Sverke, M. (Ed.), The Individual in the Changing Working Life, Cambridge University Press, Cambridge, UK, pp. 235-257.

Pienaar, J. and Rothman, S. (2003), “Coping strategies in the South African Police Service”, South African Journal of Industrial Psychology, Vol. 29, pp. 81-90.

Ragins, B. R., \& Cotton, J. L. (1993). Gender and willingness to mentor in organizations. Journal of Management, 19, 97-111.

Ragins, B. R., \& Cotton, J. L. (1999). Mentor functions and outcomes : a comparison of men and women in formal and informal mentoring relationships. Journal of Applied Psychology, Vol. 84 N. 4, 529-550.

Ragins, B. R., \& Scandura, T. A. (1999). Burden or blessing? Expected costs and benefits of being a mentor. Journal of Organizational Behavior, 20, 493-509.

Rotondo, D., Carlson, D. and Kincaid, J. (2003), “Coping with multiple dimensions of work-family conflict”, Personnel Review, Vol. 32, pp. 275-296.

Scandura, T. A. (1992). Mentorship and career mobility: An empirical investigation. Journal of Organizational Behaviour, Vol.13, pp.169-174.

Scandura, T. A. \& R. E. Viator. (1994). "Mentoring in Public Accounting Firms: Analysis of Mentor-Protégé Relationships, Mentorships, Functions \& Protégé Turnover Intentions”, Accounting, Organizations \& Society, Vol. 19, No.8, pp. 717-734.

Selmer, J. and Lauring, J. (2011). Acquired demographics and reasons to relocate among self-initiated expatriates. The International Journal of Human Resource Management, vol. 22, No. 10, pp. 2055-2070.

Shen, Y. and Kram, K.E. (2011), “Expatriates' developmental networks: network diversity, base, and support functions”, Career Development International, Vol. 16 No. 6-7, pp. 528-552.

Shen, Y. and Hall, D.T. (2009), "When expatriates explore other options: retaining talent through greater job embeddedness and repatriation adjustment”, Human Resource Management, Vol. 48 No. 5, pp. 793-816.

Snow, D., Swan, S., Raghavan, C., Connel, C. and Klein, I. (2003), "The relationship of work stressors, coping and social support to psychological symptoms among female secretarial employees”, Work and Stress, Vol. 17, pp. 241263.

Spillane, J., Konanahalli, A. and Meding, J. (2012), "International projects and cross-cultural adjustments of British expatriates in Middle East: a qualitative investigation of influencing factors", Australian Journal of Construction Economics and Building, Vol. 12 No. 3, pp. 31-54.

Stahl, G.K. (2000), "Between ethnocentrism and assimilation: an exploratory study of the challenges and the coping strategies of expatriate manager”, Academy of Management Conference Proceedings PEi.

Stroh, L.K., Gregersen, H.B. and Black, J.S. (1998), “Closing the gap: expectations versus reality among expatriates”, Journal of Business Management, Vol. 11 No. 4, pp. 111-124. 
Sullivan, S.E., Carraher, S.M. and Crocitto M.M. (2005), “Global mentoring as a means of career development and knowledge creation: a learning-based framework and agenda for future research”, Career Development International, Vol. 10 No. 6-7, pp. 522-535.

Trembath, J.-l. (2015), “A Systematic Review of the Literature on Expatriate Academics: Themes of Uncertainty for Individuals and Institutions”, $15^{\text {th }}$ annual EURAM conference, Warsaw, Poland, $17-20^{\text {th }}$ of June.

Templer, K.J. (2010), "Personal Attributes of Expatriate Managers, Subordinate Ethnocentrism, and Expatriate Success: A Host-Country Perspective”, International Journal of Human Resource Management, Vol.21, No.10, pp.1754-1768.

Tungli, Z. and Peiperl, M. (2009), "Expatriate practices in German, Japanese, U.K., and U.S. multinational companies: a comparative survey of changes”, Human Resource Management, Vol. 48 No. 1, pp. 153-171.

Toh, S.M and DeNisi, A.S. (2005), “A local perspective to expatriate success”, Academy of Management Executive, Vol. 19 No. 1, pp. 132-146.

Van Bakel , M. Van Oudenhoven , J. P. and Gerritsen , M. (2015) "Developing a high quality intercultural relationship: expatriates and their local host", Journal of Global Mobility, Vol. 3 (1), pp. 25 - 45

Wenger, E. (1998), Communities of Practice: Learning, Meaning, and Identity, Cambridge University Press, US.

Yin, R. K. (1994), Case Study Research: Design and Methods (2nd ed.), Sage Publications, Newbury Park, CA.

Zhuang, W-L, Wu, M \& Wen, S-L,( 2013) Relationship of mentoring functions to expatriate adjustments: comparing home country mentorship and host country mentorship. The International Journal of Human Resource Management, 24(1), pp. 35-49. 